\title{
Analysis of preferences of agro-pastoralists for the attributes of traction dromedaries in harness cultivation: A case study of the Koro district of Mali
}

Bakary Traoré ${ }^{1,6^{*}}$, Benoit Govoeyi ${ }^{2}$, Issa Hamadou ${ }^{3}$, Fikremariam Geda ${ }^{1}$, Abdoulaye Touré, Bara Ouologuem ${ }^{4}$, Pascal Leroy ${ }^{1,5}$, Nicolas Antoine-Moussiaux ${ }^{1,5}$ and Nassim Moula ${ }^{1,5}$

\begin{abstract}
The aim of this study was to characterize agro-pastoralists' preferences in dromedary rearing in the Koro district of Mali, which has experienced a decade of spontaneous development in using dromedaries for harnessed cultivation. Five criteria for assessment of dromedary types used for traction were identified through nine focus group discussions. The assessment criteria developed and estimated rates were the morphological characteristics (23.2\%), disease resistance (14.1\%), work attitude (26.3\%), colour of the coat (25.3\%) and docility (11.1\%). A multi-attribute analysis method was applied with 115 dromedary owners. Conditional logit was used to estimate utility function and willingness to pay (WTP) for different attributes. Work attitude seems to be an important parameter for decision-making with a WTP amounting to 558.94 euros (614.94 USD). Disease resistance comes second position in decision-making for the selection of dromedaries, with a WTP of 348.77 euros (383.40 USD). To a lesser extent, the white coat with a WTP in the order of 54.45 euros (59.86 USD) intervenes in agro-pastoral decision-making. The agro-pastoralists have a strong reluctance for the dark brown coat. In conclusion, the present results showed that further studies should be conducted on materials and traction technologies to promote harnessed cultivation by dromedaries to preserve and strengthen the multi-functional nature of the dromedary.
\end{abstract}

Keywords: Dromedary, Selection criteria, Declared preferences, Agro-pastoralists, Koro district of Mali

\section{Introduction}

The camelid Old World (dromedaries and camels) is only about $1 \%$ of the world population of domestic ruminants (Faye et al. 2013). They are found in all drylands of the world (35 million $\mathrm{km}^{2}$ ) (Wilson 2013) and are also found in area of relatively high rainfall (agricultural) areas in Russia, Iran, Turkey, northern Africa, Pakistan, and India. However, Faye (2014) indicates that they are absent in the southern part of the African continent. The arid regions are excellent breeding areas, which shelter about $50 \%$ of the global livestock. The dromedaries are multi-functional

\footnotetext{
* Correspondence: imzkoul@gmail.com

${ }^{1}$ Fundamental and Applied Research for Animal Health (FARAH), Faculty of Veterinary Medicine, University of Liege, Boulevard de Colonster, 20, building B43, 4000 Liege, Belgium

${ }^{6}$ Bamako, Mali

Full list of author information is available at the end of the article
}

animals with excellent abilities to adapt to difficult conditions and climate change, while considerably contributing to improved living conditions of the local populations (Adamou 2009; Al-Juboori et al. 2013). In Mali, the livestock industry plays an important role in the national economy. It represents nearly $30 \%$ of the primary sector contribution to gross domestic product (GDP) and 9\% of the national GDP (Samaké et al. 2008). The different periods of drought (1972-1973, 1985-1985 and 2002) experienced by Mali brought awareness on one hand about the vulnerability of traditional pastoral systems and on the other hand to the economic, social and cultural importance of dromedaries for pastoral populations in the northern zone. The number of dromedaries in Mali is about 1 , 008,540 heads (DNPIA 2016). The exceptional adaptation of the dromedary to arid and semi-arid regions (Wilson 1984) led to an increasing substitution of cattle by 
dromedaries by some nomads (Traoré et al. 2014) and the increasing introduction of the dromedary for traction in certain areas of the Mopti region. Despite the critical importance of the dromedary, development efforts in the field of animal husbandry have been primarily directed to cattle at the expense of small ruminants and dromedaries (Bidjeh et al. 1991).

Certainly, the proportion of the dromedary breeding in respect to the national needs for animal products is still low $(<2 \%)$. However, its numerical and social importance is in contrast with development and research efforts dedicated to this industry. The first investigations on dromedaries were conducted in the 1980s. Research efforts, however, remained very limited, for instance, to some surveys about their breeding systems and health (Traoré et al. 2014). In Mali, the use of animal power in agriculture continues to progress in annual crop production systems in the semi-arid and sub-humid regions.

The widespread use of dromedaries as traction animals in North Africa, Ethiopia, India, Pakistan and Afghanistan (Köhler-Rollefson 2004) is poorly practised in West Africa (Faye et al. 2013).

This study applied the technique of multi-attribute selection experiment to determine the appreciation of dromedary types by agro-pastoralists of the Koro district in Mali. It aimed to identify different attributes of dromedaries as traction animals in the form of willingness to pay (WTP) and willingness to accept compensation, in order to better understand the logic of agro-pastoralists and to identify the research and improvements needed in rearing dromedaries in the southern and central regions of Mali.

\section{Study area}

Koro district is located southeast of the Mopti region between $13^{\circ} 38^{\prime}$ and $14^{\circ} 50^{\prime} \mathrm{N}$ latitude and $2^{\circ} 00^{\prime}$ and $3^{\circ}$ $25^{\prime} \mathrm{W}$ latitude. It has an area of $10,937 \mathrm{~km}^{2}$ with a population of 362,587 inhabitants (Institut National de la Statistique, 2013). It is divided into 16 communities and 313 villages (Fig. 1). The main ethnic groups of the district are Dogoni, Peulhs, Mossis and Tellems. Agriculture and livestock are the main economic activities of the district. They are practised in all the different sociocultural layers of the population. On the agro-climatic level, there are five main agro-ecological entities: (i) the Gondo plain, (ii) the Sourou plain, (iii) the Séno, (iv) the Mondoro and (v) the Dogon highlands. The vegetation consists of woody species such as Combretum micranthum, Balanites aegyptiaca, Tamarindus indica, Amanithe goyances, Adansonia digitata, Prosopis africana, Sclerocar gabirrea, Boscia senegalensis, Acacia albida and Acacia raddiana and the herbaceous species-Schoenefeldia gracilis, Loudetia togoensis, Cenchrus biflorus, Zornia glochidiata and Andropogon gayanus.
Agriculture covers more than $60 \%$ of the total area of Koro district. There are no permanent water sources like rivers in the district with the exception of some temporary pools. The rainy season, the duration of which rarely exceeds 2 months, is characterized by low rainfall $(<700 \mathrm{~mm} /$ year $)$.

\section{Materials and methods \\ Study design}

The study was conducted in nine municipalities of Koro district. A participatory survey (focus group discussion (FGD)) was carried out to identify the main criteria used by agro-pastoralists for assessing the type of dromedary as traction animal. The results of this first phase of inquiry identified the selection attributes and the methods to be considered in the development of individual interview guides to assess the willingness to pay (WTP) for the dromedary used for agricultural and domestic work in Koro district.

\section{Participatory survey on the criteria for selection of traction dromedary \\ Focus group discussions (FGDs)}

The criteria for assessing the types of dromedaries used for traction were identified in FGDs. The degree of security and accessibility was taken into account in the choice of municipalities and village respondents. In each town, the precise areas of dromedary breeding concentration were identified with the help of village chiefs and livestock technical services. A total of nine FGDs were conducted in nine dromedary breeding areas. The FGDs involved the village heads and the technicians breeding and responsible for each concentration of the breeding area. In order to have an exhaustive list of these criteria, the transect walk method allowed us to consider the different stakeholders of the agricultural zones. Each FGD was composed on average of eight to nine participants. In each FGD, the talk primarily concentrated on the selection criteria of traction dromedaries. The main criteria listed were written and represented by symbols on PADEX paper (Fig. 2). The proportional stacking-up method was used to evaluate the relative importance of each attribute and modality. During the discussions, notes were taken and the reasons for choice and disagreements were carefully studied through open questions.

\section{Selection criteria and methods}

In the FGDs conducted in the nine livestock concentration areas, discussions revolved around the following attributes: morphological characteristics, disease resistance, work attitude, colour of the coat and market value. The identification of these attributes and the collection of individual data from agro-pastoralists were carried out in the nine communities of the Koro district. The proportional piling was performed on the selected attributes and 


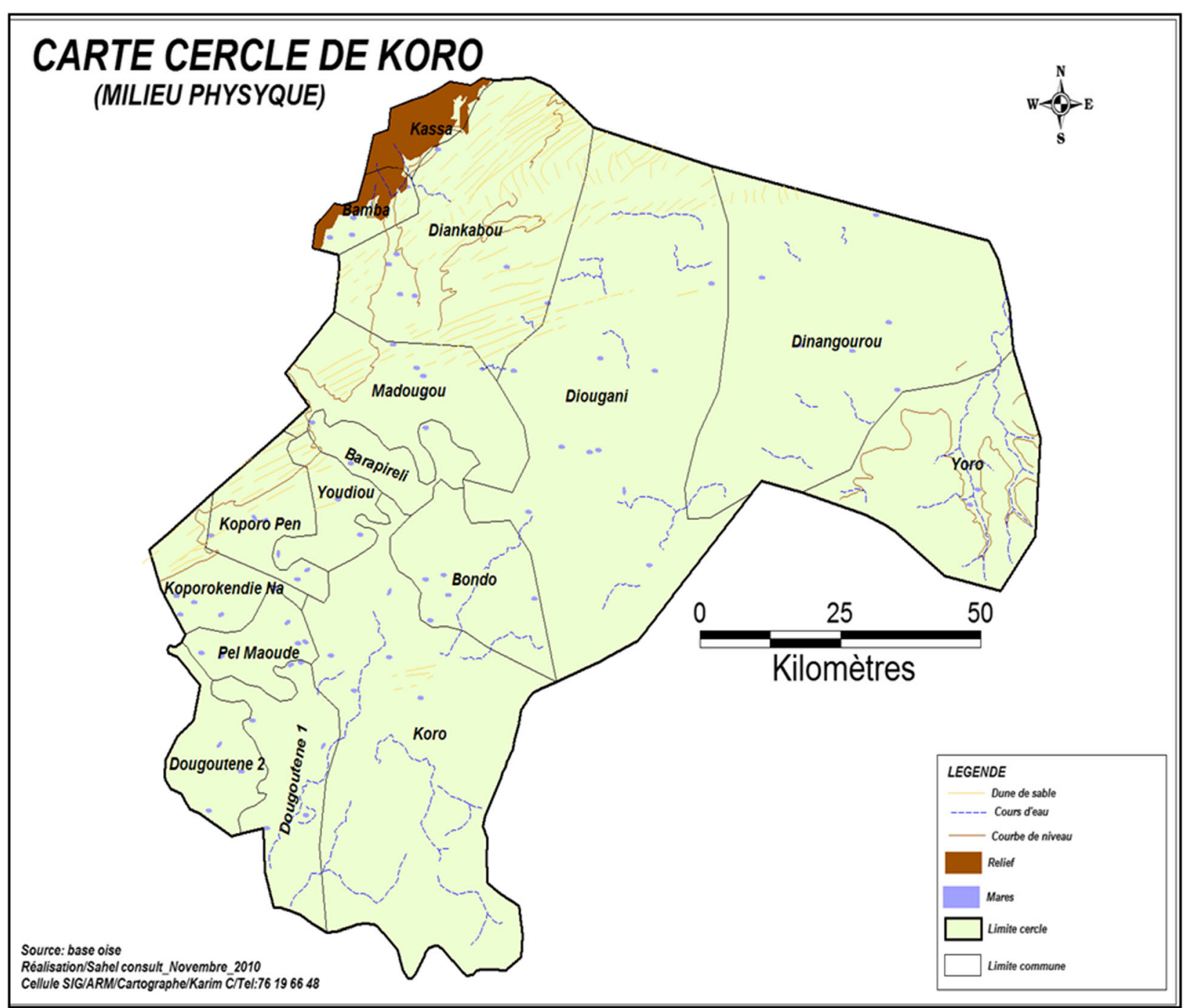

Fig. 1 Map showing communities surrounding the Koro district of Mali

conditions. Details of the five criteria around which the discussions focused on the completion of the interview guide for the continuation of the study are:

1. Morphological characteristics: This feature describes the size of the animal.

2. Disease resistance: It refers to the degree of unresponsiveness to the dominant diseases in terms of the frequency of the disease on average over the year.

3. Work attitude: This character appeared as a very important trait, based on motivations for using the dromedary as animal traction. This attribute assesses the work attitude according to the analysis of agro-pastoralists involved in the study.

4. Colour of the coat: Here the colour feature describes three key colours of dromedary coat encountered in the study area.
5. Market value: Following the models of multiattribute analysis, the attribute "price" was added on the basis of data collected in the livestock markets in the area.

Three levels were determined, namely 250,000 FCFA (419.93 USD) ( 382 EUR), 275,000 FCFA (460.61 USD) ( 419 EUR) and 400,000 FCFA (670.57 USD) ( 610 EUR), which represent respectively the minimum price, the median and the third quartile corresponding to the sale price of a dromedary on the local market during the period of January 2018. The combination of different levels of these five attributes and their terms has generated two options for 20 dromedary profiles used in individual surveys. The first 20 profiles are option 1 and the other 20 profiles, option 2 of the selection to be made by the agro-pastoralist. The third option was 


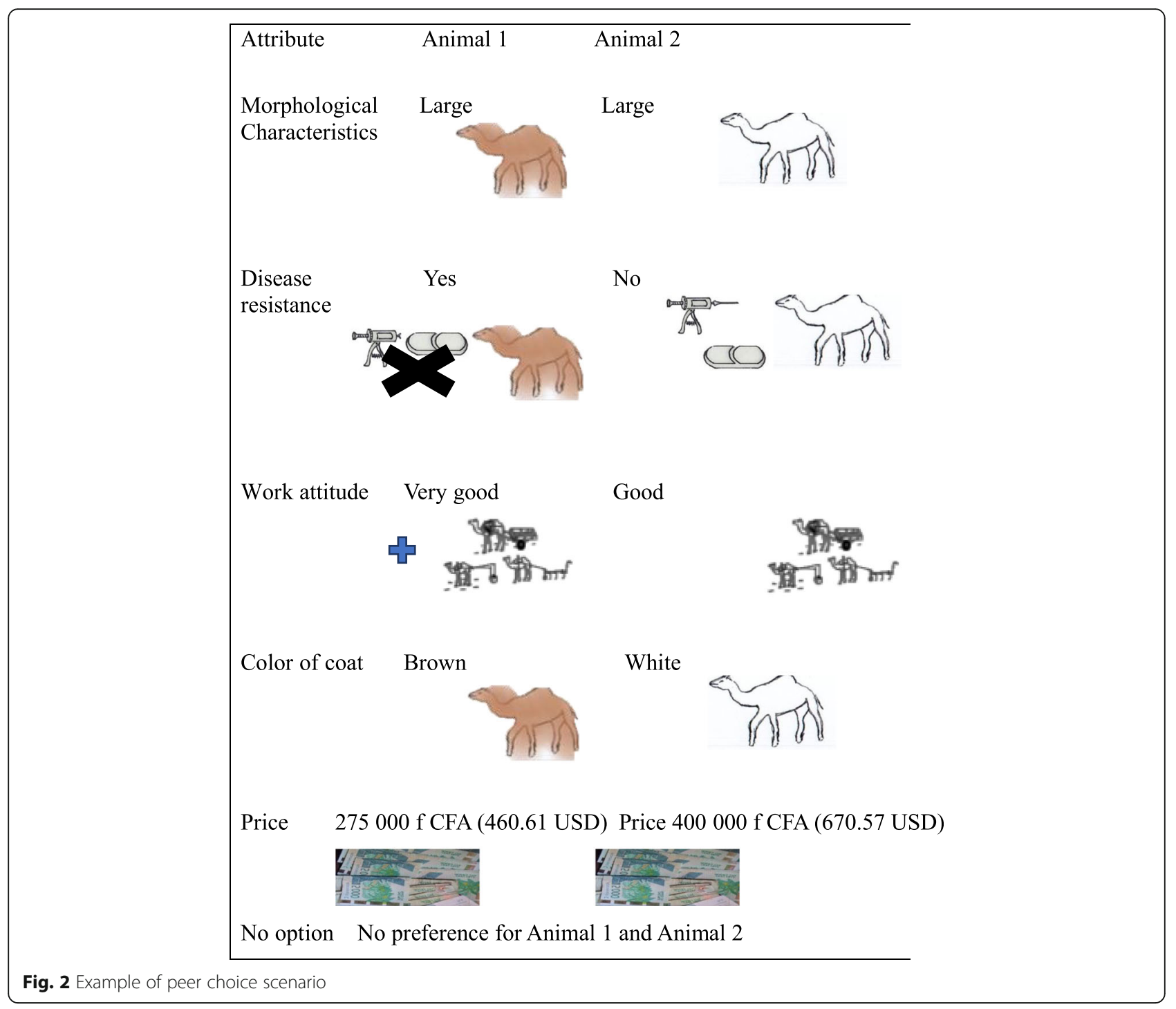

selected if none of the first two options was of an interest for the interviewee. A copy of the selection scenario with illustration is shown in Fig. 2.

\section{Sampling and interviews}

In the framework of this study, individual surveys directed us to 115 agro-pastoralists throughout the Koro district. The snowball method was used. The participants of the FGDs (village leader, rural development technician, agropastoralists) guided us to agro-pastoralists who in turn permitted us to contact other agro-pastoralists of secured villages. The main criteria to be met by a producer to be included into the sample of the survey were to possess dromedaries and be responsible for making decisions about the use of the dromedary in agricultural and domestic work. In the face-to-face interview, 20 pairs of dromedary profiles were presented to each agro-pastoralist interviewed. The interviewee was asked to choose the animal he would like to buy. The interviewee had for each pair of profiles the possibility of rejecting it, that is to say, to declare that neither of the two profiles of the pair was acceptable. At the end of the interview, the interviewee's motivations for the selection were collected and documented along with the difficulties encountered in the breeding industry.

\section{Statistical analysis and assessment of WTP}

The econometric analysis of the declared preferences was performed with the $\mathrm{R}$ software (R3.0.1, survival package, package support.CEs) (Aizaki 2012). The assessment of the utility coefficients was done using the conditional logit model. The conditional logit model is based on the random utility model which, according to 
Louvière et al. (2010), is divided into two parts: one systematic, $V_{i n}$, and the other random, $\varepsilon_{i n}$. Formally, the utility function is written:

$$
U_{\text {in }}=V_{i n}+\varepsilon_{i n}
$$

with $U_{i n}$ the utility of the individual $n$ for scenario $i$, $V_{i n}$ the systematic component of utility and $\varepsilon_{i n}$ the unobservable component of utility, considered as a random component.

The probability of selection of one of these dromedary profiles $i$ is:

$$
\operatorname{Pr} \cdot\{i \text { is chosen }\}=\operatorname{Pr}\left\{\left\{V_{n i}+\varepsilon_{n i} \geq V_{n j}+\varepsilon_{n j} ; \text { for all } \in C_{i}\right\}\right\}
$$

This is where all of the breeder's choice for $n\left(C_{n}=\right.$ $\{1,2,3\})$, choose $3=$ "No choice". For each individual $n$, the utility provided by the choice of scenario $i$ is of the form.

With $\alpha_{i}$ the constant specific to the scenario $i$ (Con) and $\beta_{k}$ the coefficients to be estimated for the $k$ attributes whose values in the scenario $i$ are represented by the $x_{i k}$.

The consent to pay corresponds to a monetary conversion utility coefficient of the level of each attribute, according to the method described by Tada et al. (2013). The consent to pay for a level I of an attribute $k$ is calculated as follows:

WTP $k 1=-\beta k 1 / \beta €$, with $\beta k 1$ as previously defined and $\beta €$ being the coefficient of utility of the monetary unit (EUR).

\section{Results}

\section{Criteria for appraising the auxiliary dromedary in agriculture}

The identification of attributes and modalities was a very important step in the design of different choice options. From the nine FGDs, five appreciation attributes of the dromedary types used for traction have been identified (Table 1). These attributes were morphological characteristics, disease resistance, work attitude, colour of the coat and docility, respectively with $23.2 \%, 14.1 \%, 26.3 \%$, $25.3 \%$ and $11.1 \%$ average proportional stacking score. The design used for the declared preference survey was developed from the four attributes with the following terms: morphological characteristics (large or small), disease resistance (yes or no), work attitude (very good, good or average) and colour of the coat (white, brown or dark brown). The docility criterion present in the results of seven working groups was excluded for two reasons. Firstly, this character is indirectly expressed with the character of work attitude. Certainly, during individual interviews, agro-pastoralists linked performance to docility; a docile animal is very efficient and easy to use, especially since the work is mainly carried out by children and women. The other reason is to have a less complex and restrictive survey system for respondents (Bateman et al. 2003; Louvière et al. 2010).

\section{WTP for agro-pastoralists' auxiliary dromedary of agriculture}

The survey for data collection of multi-attribute analysis involved 115 agro-pastoralists. The different utility coefficients are shown in Table 2. A reference level was defined for each attribute, so the coefficients of the other levels represent the value obtained by a change of reference level at the level examined. The utility coefficient of the monetary unit is negative $(-0.00714)$ and significant $(p<0.001)$. Regarding the colour of the coat, white was very popular and highly significant $(p<$ 0.001). The dark brown coat dromedary was less appreciated compared to the other two colours (white and brown). Its utility coefficient was negative but statistically very significant. The appreciation of the large body size was negative and statistically significant. Marginal utility was positive but not significant for work attitude (very good and good) as well as for disease resistance (Table 3). The results concerning the various WTP in euros were, amongst others, large format (-58.63) (64.45 USD) with a 97.5\% confidence interval (CI) of [-113.78, - 3.26] $(125.08,3.58)$, resistant to diseases (348.77) (383.40 USD) with a CI [256.93, 487.77] (282.44, 536.21), very good at work attitude (558.94) (558.94 USD) with a $97.5 \%$ CI of [418.25, 805.51] (459.78, 885.50), good at work attitude (222.09) (244,14 USD) with $97.5 \%$ CI of [137.63, 355.78] (151.30, 391.11), the white coat (54.45) (59.86)

\begin{tabular}{|c|c|c|c|c|c|}
\hline Criteria & Quote rate (\%) & Proportional stack score (\%) & Average & Min & Max \\
\hline Morphological characteristics & 100 & 23.2 & 23 & 8 & 41 \\
\hline Work attitude & 100 & 26.3 & 27 & 15 & 50 \\
\hline Colour of the coat & 100 & 25.3 & 25 & 10 & 47 \\
\hline Docility & 85 & 11.1 & 13 & 0 & 30 \\
\hline Disease resistance & 100 & 14.1 & 14 & 5 & 27 \\
\hline
\end{tabular}

Table 1 Proportional stacking on the criteria of agricultural dromedaries in nine FGDs of agro-pastoralists in the Koro district of Mali 
Table 2 Utility coefficients and WTP estimated for dromedary attributes in the Koro district of Mali

\begin{tabular}{llll}
\hline Attribute & Marginal utility & WTP (EUR) & Cl 97.5\% (EUR) \\
\hline Morphological characteristics & $0.78 \pm 0.22$ & $109.84(120.75)$ & {$[54.57,172.07](59.99,189.16)$} \\
Disease resistance & $-2.09 \pm 0.18$ & $-293.81(322,99)$ & {$[-432.41,-216.16](-475.35,-237.62)$} \\
Work attitude & $-1.97 \pm 0.14$ & $-275.70(303.08)$ & {$[-407.14,-205.78](-475.57,-226.21)$} \\
Colour of the coat & $0.23 \pm 0.11$ & $32.50(35.73)$ & {$[2.44,72.55](2.68,79.75)$} \\
Price & $-0.00714 \pm 0.0012$ & & - \\
\hline
\end{tabular}

WTP willingness to pay, $\mathrm{Cl}$ confidence interval

with $97.5 \%$ CI of $[-26.42,143.01](29.04,157.21)$ and the dark brown coat $(-90.012)$ (98.95 USD) with a $97.5 \%$ CI of $[-179.19,-27.22](196.98,29.92)$.

Work attitude seems to be an important parameter for decision-making, and it is the most important parameter with a WTP amounting to 558.94 euros (614.44 USD). The value of this single character corresponds to $92 \%$ of the highest purchase price of the dromedary used in the protocol of the multi-attribute analysis. Disease resistance comes second in decision-making for the selection of dromedaries, its WTP reaching 348.77 euros (383.40 USD) being more than half the price of an adult dromedary. To a lesser extent, the white colour of the coat with a WTP of the order of 54.45 euros (54.45 USD) intervenes in the decision-making of agro-pastoralists.

\section{Discussion}

\section{Methodology}

This study was conducted on a sample of 115 agropastoralists. Omondi et al. (2008) indicated that for such kind of study, a minimum sample size of 100 respondents is required. The coefficient associated with the constant obtained in the conditional logit has a positive and insignificant value, hence the relevance of the reference profile. Accordingly, there is no bias in the reference and the results are not compromised as indicated by Scott (2001). Different selection criteria of dromedaries included in the stated preference protocol were identified from a participatory process, investigations using FGDs, and are proportional piling. Taking into account the point of view of agropastoralists is essential for the promotion of ownership and sustainability of an animal genetic resources management programme (Hamadou et al. 2016). Similar approaches have been advocated by other authors to define the selection targets and the preferred characteristics of the sheep race Koundoum in Niger (Hamadou et al. 2016), local goats in Ethiopia (Gebreyesus et al. 2013) and to characterize the Simien sheep in Ethiopia (Melaku et al. 2012).

In the present study, the interviewee had the possibility for each pair of profiles to opt out or to choose the zero option, meaning to declare none of the profiles acceptable. When the products are very similar, sometimes the consumer selects none. The reason for such behaviour is uncertainty in the choice of products (Ohannessian 2008). Thus, the consumer prefers not to select products until he is sure of his choice. At the end of this exercise, through a discussion session, the motivations and the perceptions of the interviewee about the non-choice can be enlightened.

Table 3 Utility coefficients and WTP estimated for dromedary attribute levels in the Koro district of Mali

\begin{tabular}{lllll}
\hline Attribute & Levels & Marginal utility & WTP (EUR) & Cl 97.5\% (EUR) \\
\hline Morphological characteristics & Large & $-0.47 \pm 0.23^{* *}$ & $-58.63(64.45)$ & {$[-113.78,-3.26](125.08,3.58)$} \\
& Small & 0 & - & - \\
Disease resistance & Yes & $2.77 \pm 0.25^{\mathrm{ns}}$ & $342.77(376.81)$ & {$[256.93,487.77](282.44,536.21)$} \\
Work attitude & No & 0 & - & - \\
& Very good & $4.52 \pm 0.35^{\mathrm{ns}}$ & $558.94(614.44)$ & {$[418.25,805.51](459.78,885.50)$} \\
Colour of the coat & Good & $1.79 \pm 0.29^{\mathrm{ns}}$ & $222.09(244.14)$ & {$[137.63,355.78](151.30,391.11)$} \\
& Average & 0 & - & - \\
& Dark brown & $-0.73 \pm 0.25^{* *}$ & $-90.012(-98.95)$ & {$[-179.19,-27.22](-196.98,-29.92)$} \\
Price & Brown & 0 & - & - \\
\hline
\end{tabular}

WTP willingness to pay, $\mathrm{Cl}$ confidence interval

${ }^{* * *} p \leq 0.001,{ }^{* *} p \leq 0.01,{ }^{\text {ns }}$ not significant at $p>0.05$ 


\section{Criteria for the assessment of the agricultural dromedary auxiliary}

To better understand the logic of use and choice of the genetic type of dromedaries for agricultural and domestic work, it is necessary to understand the choice preferences of agro-pastoralists concerning their breeding decisions of dromedories. Several authors (Jabbar et al., 1999; Tada et al. 2013; Bayou et al. 2014) have mentioned the need to understand the preferences of pastoralists in relation to their livestock rearing decisions. The use of a multiattribute choice experiment method allows valuation of the preferences of farmers, expressed as WTP or receive compensation for different levels of dromedary characteristics proposed for animal traction. In fact, the experience of selection makes it possible to determine individual preferences by submitting several virtual choice tasks to the interviewees (Hanley et al. 1998; Mangham et al. 2009).

Particularly in developing countries, the preferred experimental methods of choice have been used extensively to estimate WTP or receive compensation, from interviewees for genetic zoo resources in various programmes of animal improvement and selection of animals in breeding (Zander et al. 2008; Tada et al. 2013). The four selection criteria in our study, namely morphological characteristics, disease resistance, work attitude (work performance) and colour of the coat, included in the survey protocol of this study are extracted from the results of the nine FGDs.

According to Kugonza et al. (2012), morphological characteristics and colour of the coat are classic criteria in traditional reproduction systems. The same considerations were cited for Koundoum sheep in Niger (Hamadou et al. 2016). The interest given to the criterion of colour of the coat seems to be based on socio-cultural aspects. The colour of the coat represents the most influential trait after the "performance" criterion of work attitude.

Work attitude is very important for Koro agropastoralists. Animal traction is a major innovation to support the development of agricultural crops, whilst helping to increase labour productivity and stimulate synergies between agriculture and livestock (Le thiec, 1996). The disease resistance criterion responds to one of the major concerns of livestock farmers, namely management of animal health, especially in this context characterized by the insufficiency of local veterinary health services and the lack of control of dromedary diseases. Similarly, Ouologuem et al. (2016) indicated the inaccessibility of veterinarians as limiting factors for livestock farmers in Mali. This may explain why agropastoralists are more willing to use disease-resistant animals. In order to preserve and reinforce the multifunctional character of the dromedary, it is necessary to carry out investigations on the farmer preferences for selection of the genetic dromedary type.

\section{Analysis of declared choices and WTP}

The appreciation of the traction dromedary is based on parameters of production, functionality and aesthetics. In traditional breeding systems, the multi-functional character is very typical (Ayalew et al. 2003). The selection criteria are based not only on productivity but also on the ability to resist diseases and also based on the colour of the coat (Röhler-Roolefson 1997). Nevertheless, depending on the farmers' breeding objectives, there are different levels of appreciation regarding preferences. In this study, work attitude is the most valued attribute, with a WTP amounting to 558.94 euros, corresponding to approximately $92 \%$ of the highest purchase price considered. As a result, work attitude seems to be the most important parameter for decision-making. The great importance given to work attitude explains the spontaneous development of the dromedary-coupled cultivation in the Koro region. The dromedary has a higher traction capacity than other domestic animals and is notably more powerful, faster and more resistant than a pair of oxen (Vall 1996).

Definitely, the Koro district has experienced a spontaneous development for a decade in using dromedaries for harnessed cultivation. The socio-political crisis affecting Mali, especially in the northern part of the country, seems to be a factor favouring the increase of dromedary numbers in the Mopti region in general and in the Koro and Bankass districts in particular. The use of dromedary traction is provoking a certain craze amongst many farmers for dromedary breeding in the Koro district. In both districts, many farmers have been raising dromedaries for about 10 years; they also use them as traction animals.

Over time, there are gradually increasing trends in changing species herd composition. This pattern has been at the centre of dromedary breeding efforts in the central and southern part of Mali. Currently, the dromedary is omnipresent in various agricultural and domestic work activities in the district of Koro. Dromedaries are replacing cattle and donkeys usually used for the same types of work, especially dromedaries are less demanding in maintenance and more efficient in the execution of field work. In addition, they provide a source of revenue through services and transport of people and goods.

For about 10 years, new dynamics have become established in using dromedaries for cultivation and transport in the district of Koro and surroundings. The dromedary plays an increasingly important role in animal traction for the farmers of Koro. The preference for disease resistance is far from being a peculiarity; it indicates the strong influence of this criterion in the decision-making of agro-pastoralists. The stake is high because dromedary diseases are less known and less controlled in Mali. Preference for disease resistance is very common, as 
evidenced by results for sheep in Kenya (Omondi et al. 2008), pigs in Vietnam (Roessler et al. 2008) and cattle in Burkina Faso and Kenya (Tano et al. 2003; Kassie et al. 2011).

A priori, the colour of the coat does not have an impact on the productivity of the animals. This trait rather gives a cultural and aesthetic value not to be underestimated; although traditionally neglected, all the dark brown dromedaries are as powerful as the white or brown ones. According to the present study, some agro-pastoralists emphasize that the white or brown coat dromedaries have higher market value than dark brown coat ones of similar size. Other authors have described that in Africa, traditional beliefs commonly associate animal colours with related factors such as benefits of consumption or sacrifice (Kugonz et al. 2012; Dossa et al. 2015). In addition, the relative importance of coat colour is a widespread factor in purchasing decisions of various farm animal species, as indicated for cattle in Niger (Siddo et al. 2015) or sheep in Niger (Hamadou et al. 2016) and in Ethiopia (Tadesse et al. 2015).

\section{Conclusion}

This study used the multi-attribute choice experiment technique to determine the appreciation of dromedary types for traction by agro-pastoralists in the Koro district of Mali. The use of stated preference method is not yet sufficiently developed in Mali, concerning dromedary breeding. The results obtained can contribute to a better understanding of the logic of agro-pastoralists and as a reference for research and improvement of dromedary rearing in Mali. Work attitude and disease resistance are important decision-making criteria in the selection of dromedaries. The results strongly indicated a negative attitude of the agro-pastoralists for the dark brown coat. Further studies should be conducted on materials and traction technologies to promote harnessed cultivation dromedary, to preserve and strengthen the multifunctional nature of the dromedary.

\section{Abbreviations \\ Cl: Confidence interval; DNPIA: National Directorate of Productions and Animal Industries; INSAT: National Institute of Statistics; WTP: Willingness to pay}

\section{Acknowledgements}

Ousmane Traoré, Saliou Guindo, Mahamadou Maïga et Moussa A Togo

\section{Authors' contributions}

BT contributed to the design, collection, analysis and interpretation of the data. He also wrote the manuscript. BG contributed to the design, collection, analysis and interpretation of the data. He read and approved the final manuscript. $\mathrm{H}$ contributed to the design, collection, analysis and interpretation of the data. He read and approved the final manuscript. FG read and reviewed the English translation of the final manuscript. AT contributed to the design, collection, analysis and interpretation of the data. He read and approved the final manuscript. BO and PL read and approved the final manuscript. NAM contributed to the design and read and approved the final manuscript. NM contributed to the design, analysis and interpretation of the data and read and approved the final manuscript. All authors read and approved the final manuscript.

\section{Funding}

BT (principal author) financed the costs of the study (data collection, writing as well as the traduction of the manuscript).

\section{Availability of data and materials}

Please contact the author for data requests, imzkoul@gmail.com.

Ethics approval and consent to participate

Not applicable

\section{Consent for publication}

Not applicable

\section{Competing interests}

The authors declare that they have no competing interests.

\section{Author details}

${ }^{1}$ Fundamental and Applied Research for Animal Health (FARAH), Faculty of Veterinary Medicine, University of Liege, Boulevard de Colonster, 20, building B43, 4000 Liege, Belgium. '2Polytechnic School of Abomey Calavy, Department of Animal Health and Production, University of Abomey Calavy, 01 BP 2009 Cotonou, Benin. ${ }^{3}$ Department of Animal Production, National Institute of Agricultural Research of Niger, BP 429 Niamey, Niger. ${ }^{4}$ Institute of Rural Economics (IER), BP 262 Bamako, Mali. ${ }^{5}$ Tropical Veterinary Institute, Faculty of Veterinary Medicine, University of Liege, Boulevard de Colonster 20, building B43, 4000 Liege, Belgium. 'Bamako, Mali.

Received: 12 March 2019 Accepted: 22 August 2019

Published online: 02 December 2019

\section{References}

Adamou, A. 2009. L'élevage camelin en Algérie: quel type pour quel avenirpleas ? Sécheresse 19: 253-260. https://doi.org/10.1684/sec.2008.0149.

Aizaki, H. 2012. Basic functions for supporting an implementation of choice experiments in R. Journal of Statistical Software (2): 1-24 http://www.jstatsoft. org/v50/c02/.

Al-Juboori, A.T., M. Mohammed, J. Rashid, J. Kurian, and S. El-Refaey. 2013. Nutritional and medicinal value of camel (Camelus dromedaries) milk. ZIT transactions on ecology and the environment 170. WIT Press. WWW.witpress. com, ISSN 1743-3541 (on-line). https://doi.org/10.2495/FENV130201.

Ayalew, W., B. Rischkowsky, J.M. King, and E. Bruns. 2003. Crossbreds did not generate more net benefits than indigenous goats in Ethiopian smallholdings. Agricultural Systems 76 (3): 1137-1156. https://doi.org/10.1016/ S0308-521X(02)00033-1.

Bateman, I.J., R.T. Carson, B. Day, W.M. Hanemann, N. Hanley, T. Hett, et al. 2003. Guidelines for the use of stated preference techniques for the valuation of preferences for non-market goods. Cheltenham: Edward Elgar Publishing.

Bayou, E., A. Haile, S. Gizaw, and Y. Mekasha. 2014. Characterizing husbandry practices and breeding objectives of Sheko cattle owners for designing conservation and improvement strategies in Ethiopia. Livestock Research for Rural Development 26 (12) [7 April 2018]. http://www.Irrd.org//rrd26/12/ bayo26235.

Bidjeh, K., K. Ganda, and C. Diguimbaye. 1991. Variole caprine au Tchad: étude du pouvoir pathogène du virus chez les ovins et les caprins. Revue d'élevage et de Médecine Vétérinaire des Pays Tropicaux 44 (1): 33-36. https://doi.org/10. 19182/remvt.9211.

DNPIA (Direction Nationale des Productions et des Industries Animales). 2016. Mali. Rapport annuel, $113 \mathrm{p}$.

Dossa, L.H., M. Sangare, A.A. Buerkert, and F. Schlecht. 2015. Production objectives and breeding practices of urban goat and sheep keepers in West Africa: Regional analysis and implications for the development of supportive breeding programs. Springer Plus 4: 281. https://doi.org/10.1186/s40064-0151075-7.

Faye, B. 2014. Anatomical and physiological adaptation of domestic animals to ecosystem constraints: The example of the camel in arid lands. Al-Farabi KNU Bull, Série Biologie 60 (1-2): 134-137 http://bb.kaznu.kz/index.php/biology/ article/view/144. 
Faye, B., G. Vias-Franck, and M. Chaibou. 2013. Autres repères, autres paysages : le dromadaire profite-t-il du changement climatique ? courier de l'environnement de I'INRA N ${ }^{\circ}$ 63:131-140; https://hal.archives-ouvertes.fr/hal01221860/file/15-C63Faye

Gebreyesus, G., A. Haile, and T. Dessie. 2013. Breeding scheme based on community-based participatory analysis of local breeding practices, objectives and constraints for goats around Dire Dawa, Ethiopia. Livestock Research for Rural Development 25 [10/04/2018]; http://www.lrrd.org//rrd25/3/ grum25048.

Hamadou, I., N. Moula, S. Siddo, M. Issa, H. Marichatou, P. Leroy, and N. AntoineMoussiaux. 2016. Socio-economic and technical aspects of the conservation of Koundoum sheep in Niger. PhD thesis, Liege University. [20 December 2017]. https://orbi.uliege.be/bitstream/2268/192980/1/THESE\%20ISSA\%2 OHAMADOU\%20version\%20finale

Hanley, N., R.E. Wright, and V. Adamowicz. 1998. Using choice experiments to value the environment. Kluwer Academic Publishers, the Netherlands. Environmental and Resource Economics 11 (3-4): 413-428. https://doi.org/10. 1023/A:1008287310583.

Institut National de la Statistique, 2013. $4^{\text {e }}$ Recensement Général de la Population et de l'Habitat 2009. Mali: Ministère de l'Économie des Finances et du Budget. Rapport final. 298 p.

Jabbar, M.A., B.M. Swallow, and E. Rege. 1999. Incorporation of farmer knowledge and preferences in designing breeding policy and conservation strategy for domestic animals. Outlook on Agriculture 28 (4): 239-243. https://doi.org/10. 1177/003072709902800407.

Kassie, G.T., A. Abdulai, C. Wollny, W. Ayalew, T. Dessie, M. Tibbo, A. Hail, et al. 2011. Implicit prices of indigenous cattle traits in central Ethiopia: Application of revealed and stated preference approaches, ILRI, Nairobi, Kenya, Research Rep. 26, 42 p.

Köhler-Rollefson I. 2004. The camel in Rajasthan: Agricultural biodiversity under threat. In: Proc. of the Int. Conf. on Saving the camel and peoples' livelihood, Sadri (India), 23-25/11/04, p. 6-18.

Kugonza, D.R., M. Nabasirye, O. Hanotte, D. Mpairwe, and A.M. Okeyo. 2012. Pastoralists' indigenous selection criteria and other breeding practices of the long-horned Ankole cattle in Uganda. Tropical Animal Health and Production 44 (3): 557-565. https://doi.org/10.1007/s11250-011-9935-9.

Le thiec G. coord. 1996. Agriculture africaine et traction animale. Montpellier, France, Cirad, 355 p. (Coll. Techniques).

Louvière, J.J., D. Pihlens, and R. Carson. 2010. Design of discrete choice experiments: A discussion of issues that matter in future applied research. Journal of Choice Modelling 4 (1): 1-8. https://doi.org/10.1016/S17555345(13)70016-2.

Mangham, L.J., K. Hanson, and B. Mcpake. 2009. How to do (or not to do) ... Designing a discrete choice experiment for application in a low-income country. Health Policy and Planning 24 (2): 151-158. https://doi.org/10.1093/ heapol/czn047.

Melaku, S., Z. Mekuriaw, S. Gizaw, and M. Taye. 2012. Community based characterization of Simien sheep based on growth performance and farmers' breeding objectives in Simien mountains region, Ethiopia. Research Journal of Animal Science 6: 47-55. https://doi.org/10.3923/rjnasci.2012.47.55.

Ohannessian, S. 2008. L'option"Zéro" en analyse conjointe: Une nouvelle spécification de l'indécision et du refus. Application au marché de la vidéo à la demande. (Unpublished PhD thesis National Conservatory of Arts and crafts of Paris). HAL Id: tel-00265910.

Omondi, I., I. Baltenweck, A.G. Drucker, G. Obare, and K.K. Zander. 2008. Economic valuation of sheep genetic resources: Implications for sustainable utilization in the Kenyan semi-arid tropics. Tropical Animal Health and Production 40 (8): 615-626. https://doi.org/10.1007/s11250-008-9140-7.

Ouologuem, B., M. Moussa, M. N'diaye, I. Baradji, S. Penda, F.G. Bore, et al. 2016. Diagnostic du système d'élevage du dromadaire dans la région de Kidal au nord-est du Mali. Livestock Research for Rural Development 28 (9) http://www. Irrd.org//rrd28/9/ouol28162.

Roessler, R., A.G. Drucker, R. Scarpa, A. Markemann, U. Lemke, L.T. Thuy, and A. Valle-Zarate. 2008. Using choice experiments to assess smallholder farmers' preferences for pig breeding traits in different production systems in NorthWest Vietnam. Ecological Economics 66: 184-192. https://doi.org/10.1016/j. ecolecon.2007.08.023.

Röhler-Rollefson, I. 1997. Indigenous practices of animal genetic resource management and their relevance for conservation of domestic animal diversity in developing countries. Journal of Animal Breeding and Genetics 114 (1-6): 231-238. https://doi.org/10.1111/j.1439-0388.1997.tb00509.x .
Samaké, A., J.F. Beleires, C. Corniaux, N. Dembélé, V. Kelly, J. Marzin, J. Staatz, and D. Gautier. 2008. Changements structurels des économies rurales dans la mondialisation. Programme Rural Struct Mali-Phase II. World Bank. http:// www.worldbank.org/afr/ruralstruc.

Scott, A. 2001. Eliciting GPs' preferences for pecuniary and non-pecuniary job characteristics. Journal of Health Economics 20: 329-347. https://doi.org/10. 1016/S0167-6296(00)00083-7.

Siddo, S., N. Moula, I. Hamadou, H. Marichatou, P. Leroy, and N. AntoineMoussiaux. 2015. Breeding criteria and willingness to pay for improved Azawak zebu sires in Niger. Archive for Animal Breeding 58: 251-259. https:// doi.org/10.5194/aab-58-251-2015.

Tada, O., V. Muchenje, and K. Dzama. 2013. Preferential traits for breeding Nguni cattle in low-input in-situ conservation production systems. Springer Plus 2: 195. https://doi.org/10.1186/2193-1801-2-195.

Tadesse, E., T. Negesse, and G. Abebe. 2015. Sheep production and marketing system in southern Ethiopia: The case of Awassazuria district. Tropical Animal Health and Production 47: 1417-1425. https://doi.org/10.1007/s11250-015-0852-1.

Tano, K., M. Kamuanaga, M.D. Faminow, and B. Swallon. 2003. Using conjoint analysis to estimate farmer's preferences for cattle trait in West Africa. Ecological Economics 45: 393-407. https://doi.org/10.1016/S09218009(03)00093-4.

Traoré, B., N. Moula, A. Touré, B. Ouologuem, P. Leroy, and N. Antoine-Moussiaux. 2014. Characterisation of camel breeding practices in the Ansongo Region, Mali. Tropical Animal Health and Production 46 (7): 1303-1312. https://doi.org/ 10.1007/s11250-014-0644-z.

Wilson, R.T. 2013. The one-humped camel in Southern Africa: Unusual and new records for seven countries in the Southern African Development Community. African Journal of Agricultural Research 8 (28): 3716-3723, 26 July, 2013. https://doi.org/10.5897/AJAR12.2165.

Vall Eric. 1996. Capacités de travail, comportement à l'effort et réponses physiologiques du zébu, de l'âne et du cheval au Nord-Cameroun. Montpellier : ENSAM, 415 p. Thèse de doctorat : Sciences agronomiques : Ecole nationale supérieure agronomique de Montpellier.

Wilson, R.T. 1984. The camel. Singapour: The print house Pte LTD.

Zander, K.K., and A.G. Drucker. 2008. Conserving what's important: Using choice model scenarios to value local cattle breeds in East Africa. Ecological Economics 68: 34-45. https://doi.org/10.1016/j.ecolecon.2008.01.023.

\section{Publisher's Note}

Springer Nature remains neutral with regard to jurisdictional claims in published maps and institutional affiliations.

\section{Submit your manuscript to a SpringerOpen ${ }^{\circ}$ journal and benefit from:}

- Convenient online submission

- Rigorous peer review

- Open access: articles freely available online

- High visibility within the field

- Retaining the copyright to your article

Submit your next manuscript at $\boldsymbol{\nabla}$ springeropen.com 